\title{
Corecovery of Bio-Oil and Fermentable Sugars from Oil-Bearing Biomass
}

\author{
Godwin Severa, ${ }^{1}$ Guneet Kumar, ${ }^{2}$ and Michael J. Cooney ${ }^{1}$ \\ ${ }^{1}$ Hawaii Natural Energy Institute, University of Hawaii, Honolulu, HI 96816, USA \\ ${ }^{2}$ Suganit Systems Inc., 10903 Hunt Club Road Reston, VA 20190-3912, USA \\ Correspondence should be addressed to Michael J. Cooney; mcooney@hawaii.edu
}

Received 27 April 2013; Revised 8 July 2013; Accepted 8 July 2013

Academic Editor: Said Galai

Copyright (C) 2013 Godwin Severa et al. This is an open access article distributed under the Creative Commons Attribution License, which permits unrestricted use, distribution, and reproduction in any medium, provided the original work is properly cited.

\begin{abstract}
The applicability of ionic liquid-methanol cosolvent system to both extract bio-oil and simultaneously pretreat the carbohydrate fraction of jatropha and safflower biomass for enzymatic hydrolysis to fermentable sugars is presented. Although pretreatment with either the cosolvent or pure ionic liquid yielded comparable hydrolysis kinetics and fermentable sugar yields on safflower whole seeds, the addition of alcohol to the ionic liquid was necessary to optimally recover both bio-oil and fermentable sugars. The ionic liquid $[\mathrm{C} 2 \mathrm{mim}][\mathrm{Ac}]$ was far more effective than $[\mathrm{C} 2 \mathrm{mim}]\left[\mathrm{MeSO}_{4}\right]$ with optimum processing conditions occurring at a cosolvent concentration of $70-30 \mathrm{wt} \%$ of $[\mathrm{C} 2 \mathrm{mim}][\mathrm{Ac}]$ to methanol and a processing temperature of $120^{\circ} \mathrm{C}$. Under these conditions, the majority of the bio-oil was extracted and $25.4 \mathrm{wt} \%$ (safflower) and $14.3 \mathrm{wt} \%$ (jatropha) of the whole seed biomass were recovered as fermentable sugars. The recovery of fermentable sugars from the carbohydrate fraction was as high as $74 \%$ and $78 \%$ for jatropha and safflower seeds, respectively, when using [C2mim] [Ac] cosolvent. A preliminary theoretical analysis of two potential oil seed processing pathways using the cosolvent system suggested that the corecovery of bio-oil, fermentable sugars, and a protein rich meal can recover a majority of the energy contained in the original biomass-a result that improves upon the traditional approach of solely extracting bio-oil.
\end{abstract}

\section{Introduction}

Fuel from biomass technology has embraced the application of green chemistry to increase utilization of biomass, minimize production of waste product, and improve recovery of nontoxic solvents. Many efforts have focused on processes that recover single components, for example, the recovery of lipids from oil bearing biomass or carbohydrates from lignocellulosic biomass [1-3]. With respect to oil-seed biomass, however, few reports have focused on treatments that recover both components [4]. From this perspective, the recovery of both fermentable sugars and bio-oil from oil-seed biomass using a single application of a common "green" solvent would represent a significant contribution to the sustainable utilization of biomass resources.

The extraction of bio-oil from oil-bearing biomass using solvent or mechanical extraction techniques has been well investigated $[2,4,12,13]$. Mechanical extraction comprises pressing the oil seed with a screw press to expel the oil and leave behind a carbohydrate- and protein-rich seed cake. Solvent extraction of bio-oil has traditionally been applied with organic solvents such as hexane under low to moderate temperatures and pressure [4]. Solvent extraction generally achieves extraction efficiencies as high as $98 \%$ whilst mechanical processes generally achieve efficiencies of less than $80 \%$ although improvements have occurred over the last decade [5]. Solvent extraction is generally considered more economical when the volume of biomass processed exceeds 250 tons per day [12].

The production of fermentable sugars from lignocellulosic biomass has also been well studied and largely focused on chemical pretreatment with dilute acids, steam explosion, or organic solvent pretreatments $[1,14-16]$. These pretreatment steps are aimed at disrupting the biomass cell wall structure as a means to increase accessibility of hydrolysis enzymes $[3,17,18]$. Unfortunately, most suffer low efficiencies, require high energy use, cause loss of fermentable sugars, or form inhibitory products which affect downstream processing $[3$, 
$14,15]$. From this perspective, a more efficient and inexpensive pretreatment process with less impact on downstream processing would improve commercial viability. Recently, room temperature ionic liquids have been proposed to fill this void $[3,19,20]$ due to their observed solvating power and perceived minimal impact upon the environment. Specifically, ionic liquids have been applied in the dissolution of cellulose, lignin, and lignocellulosic biomass [16, 19, 21-23].

More recently, ionic liquid based cosolvents have been shown in our lab to efficiently extract bio-oil and amphiphilic molecules from oil-seed biomass [24, 25]. In the specific case of jatropha biomass, the cosolvent was shown to extract and solubilize phorbol esters while partitioning the extracted biooil to its own separate immiscible phase. Given the reported qualities of pure solutions of ionic liquids to pretreat biomass, the question was raised as to whether the cosolvent extraction process could also pretreat the carbohydrate fraction of the biomass for subsequent enzymatic hydrolysis to recover simple sugars. To this end, this work reports on the capacity of the cosolvent to concomitantly recover both bio-oil and fermentable sugars from jatropha and safflower biomass. Commentary is given on the input-output efficiency of the cosolvent extraction system as well as how the cosolvent disrupts the various components of the biomass and how this relates to the efficiency of enzymatic hydrolysis.

\section{Experiment}

2.1. Materials and Chemicals. Methanol (Fisher scientific), 1-ethyl-3-methylimidazolium acetate ([C2mim][Ac]), 90\% (Aldrich), 1-ethyl-3-methylimidazolium methyl sulfate ([C2mim] $\left.\left[\mathrm{MeSO}_{4}\right]\right), 98 \%$ (Aldrich), sulfuric acid (Fisher Scientific), hexane (Fisher scientific), CTec2 enzyme solution (Novozymes Inc.), HTec2 enzyme solution (Novozymes Inc.), glucose (Sigma Aldrich), and xylose (Sigma Aldrich) were used as received from manufacturer. $18 \mathrm{M} \Omega \mathrm{cm}$ deionized, filtered water was used to make aqueous solutions (Barnstead E-pure water purification system). Jatropha seeds were obtained from University of Hawaii, Department of Tropical Plant and Soil Science and safflower seeds were obtained from Pacific Biodiesel Inc. The safflower whole seeds were ground as received with a blender. The jatropha whole seeds (kernel plus shell) were either ground as received with a blender or deshelled and the separated shells and kernels weighed and ground separately using a blender. The composition of safflower seeds was $14 \%$ crude protein, $39 \%$ bio-oil, 29\% carbohydrates, 6\% moisture, and 12\% lignin. Jatropha whole seed had $20 \%$ crude protein, $31 \%$ bio-oil, $22 \%$ carbohydrates, $8 \%$ moisture, and 19\% lignin. The protein content was determined by Kjeldahl method, bio-oil by solvent extraction method, carbohydrate by difference (100 - bio-oil (\%) - proteins (\%) - lignin (\%) - moisture (\%)) and lignin by pyrolysis method.

2.2. Ionic Liquid Pretreatment prior to Carbohydrate Hydrolyses. Ionic liquid pretreatment of biomass comprised heating the biomass in sealed glass tubes filled with the ionic liquid based cosolvent at temperatures between 64 and $120^{\circ} \mathrm{C}$. The ionic liquid ([C2mim] $\left[\mathrm{MeSO}_{4}\right]$ or $\left.[\mathrm{C} 2 \mathrm{mim}][\mathrm{Ac}]\right)$ was mixed with methanol at different weight ratios to a final total mass of 3.2 grams. The jatropha kernel was treated at $120^{\circ} \mathrm{C}$ for 5 hours. The safflower whole seed was treated at 64,100 , and $120^{\circ} \mathrm{C}$ for 5 hours. The jatropha whole seed (i.e., kernel and shell) and shell were treated for 5 hours at $120^{\circ} \mathrm{C}, 100$, and $120^{\circ} \mathrm{C}$, respectively. In all cases at least 0.8 grams of biomass was used with the 3.2 grams of cosolvent to yield a solids loading of approximately $20 \%$ (w/w). Upon completion of the pretreatment process, the mixture was centrifuged at $6260 \mathrm{rpm}$ for 10 minutes producing three phases: a bottom biomass phase, a middle cosolvent phase, and a top lipid phase. The only exception to this observation was with the treatment of shell biomass which did not produce a top bio-oil (lipid) phase. The top lipid phase was recovered as reported previously [24, 26]. Approximately $10 \mathrm{~mL}$ of methanol was added to the combined bottom biomass and cosolvent phases in order to ensure complete precipitation of the carbohydrates and the mixture was centrifuged at $6260 \mathrm{rpm}$ for 10 minutes. The bottom biomass phase was then separated from the middle cosolvent phase by decantation and washed two times with $10 \mathrm{~mL}$ of water and a final third time with $10 \mathrm{~mL}$ of $50 \mathrm{mM}$ citrate buffer at $\mathrm{pH} 4.8$.

2.3. Carbohydrate Hydrolyses Assay. The application of enzymatic hydrolysis across samples differed depending upon the manner in which the biomass was originally processed. Untreated biomass (i.e., controls) and biomass samples (pretreated as described in Section 2.2) were suspended in $50 \mathrm{mM}$ citrate buffer at $\mathrm{pH} 4.8$ at a solids loading of about 5\% $(\mathrm{w} / \mathrm{w})$. To these biomass-citrate buffer mixtures dosages of Novozymes' CTec2 (for cellulose digestion) and Htec2 (for hemicellulose digestion) hydrolysis enzyme solutions were added to a final weight percent (relative to the biomass) of $12.5 \%$. The sample mixtures were then agitated slowly between 45 and $50^{\circ} \mathrm{C}$ for 72 hours after which time aliquots of the mixture were syringe filtered through 0.22 um pore size filters and frozen until subsequent HPLC analysis of glucose and xylose sugar content.

2.4. HPLC Analyses of Hydrolyzed Sugars. The hydrolyzed samples from Section 2.3 were injected onto a Bio-Rad (HPX$87 \mathrm{H}$ ) column using $5 \mathrm{mM} \mathrm{H}_{2} \mathrm{SO}_{4}$ as the mobile phase. The separation was achieved at $55^{\circ} \mathrm{C}$ using a flow rate of $0.4 \mathrm{~mL} \mathrm{~min}^{-1}$. Calibration curves were made with aqueous standard solutions of glucose and xylose. The retention times of glucose, and xylose were 13.3 and $14.3 \mathrm{~min}$, respectively. Unless otherwise stated, carbohydrate yields are reported as weight percent fermentable sugars, glucose and xylose, relative to the initial mass of the biomass (that is whole seed, shell, or kernel) which includes the bio-oil, protein, and carbohydrate fractions. As such that carbohydrate yields may appear low relative to the literature-reported values for biomass that were almost entirely cellulosic in nature (i.e., woods).

2.5. Scanning Electron Microscopy. Dried specimens of hydrolyzed biomass were mounted on aluminum stubs using silver paste and sputtered with gold/palladium in a Hummer 6.2 sputter coater. Images were viewed using a Hitachi 
TABLE 1: Weight percent fermentable sugars recovered from safflower whole seeds pretreated with $[\mathrm{C} 2 \mathrm{mim}][\mathrm{Ac}]-\mathrm{MeOH}$ at 64,100 , and $120^{\circ} \mathrm{C}$. Yields are reported relative to weight of whole seed.

\begin{tabular}{|c|c|c|c|c|c|c|}
\hline \multirow{3}{*}{$\mathrm{wt} \%[\mathrm{C} 2 \mathrm{mim}][\mathrm{Ac}]$} & \multicolumn{6}{|c|}{ Safflower whole seed (wt $\%$ glucose, xylose) ${ }^{\mathrm{a}}$} \\
\hline & \multicolumn{2}{|c|}{$64^{\circ} \mathrm{C}$} & \multicolumn{2}{|c|}{$100^{\circ} \mathrm{C}$} & \multicolumn{2}{|c|}{$120^{\circ} \mathrm{C}$} \\
\hline & glucose & xylose & glucose & xylose & glucose & xylose \\
\hline $45 \%$ & $11.8(0.1)$ & $3.1(0.0)$ & $13.7(0.2)$ & $5.4(0.5)$ & $15.4(0.4)$ & $7.3(0.2)$ \\
\hline $60 \%$ & - & - & - & - & $16.4(0.5)$ & $7.3(0.4)$ \\
\hline $70 \%$ & $11.2(0.3)$ & $3.5(0.0)$ & $15.4(0.3)$ & $7.0(0.1)$ & $17.4(0.2)$ & $8.0(0.2)$ \\
\hline $80 \%$ & - & - & - & - & $17.3(0.3)$ & $7.6(0.1)$ \\
\hline $100 \%$ & $12.1(0.0)$ & $3.5(0.2)$ & $14.5(0.2)$ & $5.9(0.2)$ & $16.7(0.2)$ & $7.5(0.1)$ \\
\hline
\end{tabular}

${ }^{a}$ The reported values are averages of at least two samples. The values in brackets are the deviations of the measured values from the mean.

S-4800 field emission scanning electron microscopy at an acceleration voltage of $10 \mathrm{kV}$.

\section{Results and Discussion}

3.1. Effect of Pretreatment on Enzymatic Hydrolysis. The safflower whole seeds possessed a total of $29 \mathrm{wt} \%$ carbohydrates relative to total biomass available for hydrolysis to fermentable sugars. The efficiency of pretreating safflower whole seeds with [C2mim][Ac]-methanol cosolvent correlated better with process temperature than with the relative proportion of [C2mim][Ac] to methanol (Table 1). Glucose and xylose yields at $64^{\circ} \mathrm{C}$ were similar to those obtained on untreated safflower whole seed (i.e., 13.1 and $4 \mathrm{wt} \%$, resp., relative to weight of whole seed, data not presented in Table 1) indicating that the pretreatment process was inefficient at this temperature. Pretreatment at $120^{\circ} \mathrm{C}$, however, increased glucose and xylose yields by approximately $56 \%$ and $112 \%$, respectively (e.g., from $11.2 \%$ to $17.4 \%$ between $64^{\circ} \mathrm{C}$ and $120^{\circ} \mathrm{C}$ for glucose at a $[\mathrm{C} 2 \mathrm{mim}][\mathrm{Ac}]$ to methanol ratio of $70: 30)$. The inefficient digestion of safflower whole seed at low temperature (i.e., $64^{\circ} \mathrm{C}$ ) in either cosolvent or pure ionic liquid likely resulted from the fact that the safflower whole seeds have a high lignocellulose composition that requires higher temperatures to initiate the breakage of the intermolecular hydrogen bonding.

With respect to the relative ratio of $[\mathrm{C} 2 \mathrm{mim}][\mathrm{Ac}]$ to methanol, the fermentable sugar yields slightly increased with increasing concentration of [C2mim] [Ac], with a maximum of yield $25.4 \mathrm{wt} \%$ (relative to weight of whole seed) achieved at a $[\mathrm{C} 2 \mathrm{mim}][\mathrm{Ac}]$ to methanol weight ratio of 70-30 after which only a slight drop off in yield was observed as the [C2mim] [Ac] concentration increased from $70 \mathrm{wt} \%$ to purity (Figure 1). The maximum yield achieved at a [C2mim][Ac] to methanol of $70 \mathrm{wt} \%$ is attributed to the impact of methanol dilution and the more efficient mixing that occurs at lower viscosity $[24,27]$.

Given the small difference in yields between 70 and $100 \mathrm{wt} \%$ [C2mim][Ac] to methanol, the rate of the hydrolysis was studied at $120^{\circ} \mathrm{C}$ (Figure 2) in order to determine if pretreatment with $70 \mathrm{wt} \%$ [C2mim][Ac] would produce much shorter hydrolysis times. The results indicate that pretreatment of safflower whole seed with [C2mim][Ac] at both 70 and $100 \mathrm{wt} \%$, however, yielded similar hydrolysis rates for cellulose and hemicellulose (Table 2), suggesting

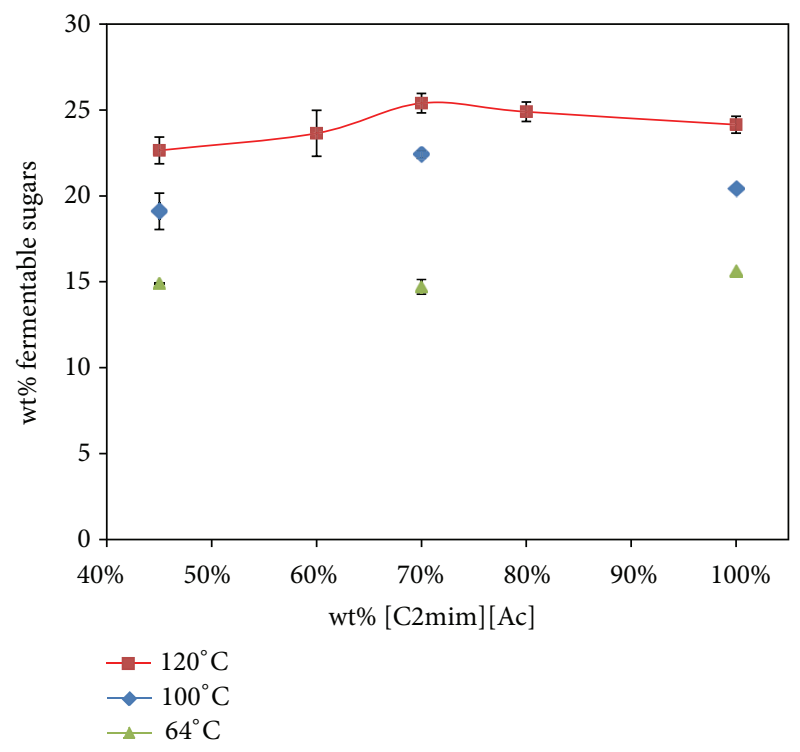

FIGURE 1: Total fermentable sugar yields relative to weight of whole seed from enzyme hydrolysis of safflower whole seed pretreated at various temperatures.

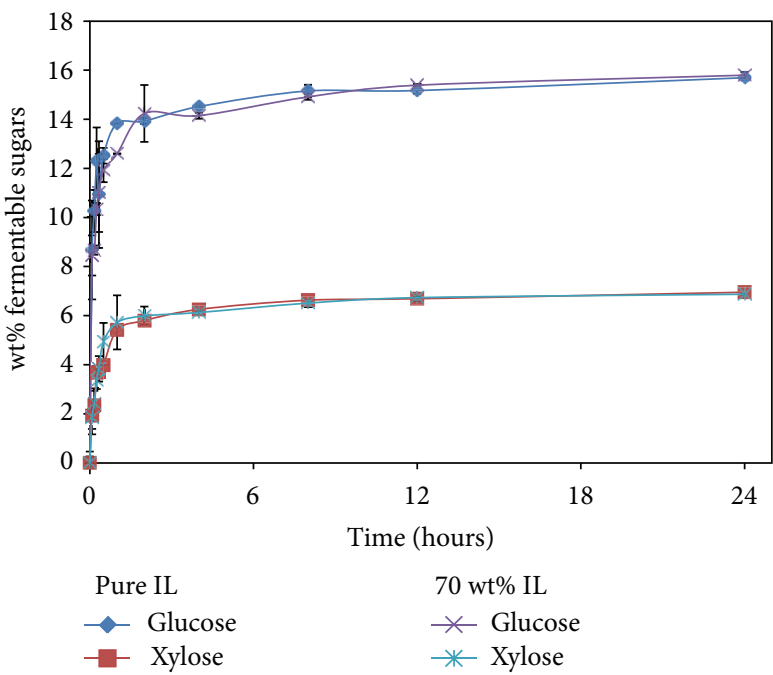

FIGURE 2: Effect of ionic liquid concentration on hydrolysis kinetics of safflower whole seed, using pure and $70 \mathrm{wt} \%$ [C2mim][Ac] at $120^{\circ} \mathrm{C}$. 
TABLE 2: Initial rates of fermentable sugar formed during hydrolysis of safflower whole seeds. Initial hydrolysis rates were calculated from the data obtained during the first 10 minutes of hydrolysis.

\begin{tabular}{lcc}
\hline \multirow{2}{*}{ wt $\%[\mathrm{C} 2 \mathrm{mim}][\mathrm{Ac}]$} & \multicolumn{2}{c}{ Initial rate of formation $(\mathrm{mg} / \mathrm{mL} / \mathrm{min})^{\mathrm{a}}$} \\
& $70 \%$ & $100 \%$ \\
\hline glucose & $0.43(0.007)$ & $0.44(0.002)$ \\
xylose & $0.12(0.022)$ & $0.12(0.019)$ \\
\hline
\end{tabular}

${ }^{\mathrm{a}}$ The reported values are averages of two samples. The values in brackets are the deviations of the measured values from the mean.

that the dilution of [C2mim] [Ac] with methanol did not significantly reduce the rate of hydrolysis.

Pretreatment of safflower whole seed with methyl sulfate as the anion, however, was ineffective. Pretreatment with $[\mathrm{C} 2 \mathrm{mim}]\left[\mathrm{MeSO}_{4}\right]$ at temperatures ranging between 64 and $120^{\circ} \mathrm{C}$ resulted in yields similar to those of untreated safflower whole seed at all temperatures, Table 3, confirming the literature-reported efficacy of acetate anion to pretreat biomass prior to enzymatic hydrolysis. The acetate anion is better able to hydrogen bond with the cellulose and to disrupt its crystalline structure, making the bonds more susceptible to enzymatic hydrolysis [20]. As such, the lower yields associated with the methyl sulfate anion are attributed to the inability of the $\left[\mathrm{MeSO}_{4}\right]$ anion to effectively interact with the cellulosic component of the biomass despite the fact that the $[\mathrm{C} 2 \mathrm{mim}]\left[\mathrm{MeSO}_{4}\right]$ based cosolvent is reported to support excellent bio-oil extraction from oil-bearing biomass [24, 25].

Following the pretreatment of safflower whole seed biomass, the effect on jatropha whole seed was similarly evaluated at $120^{\circ} \mathrm{C}$ but using only acetate as the anion (Figure 3 ). The efficiency of fermentable sugar production increased slightly as the relative concentration of $[\mathrm{C} 2 \mathrm{mim}][\mathrm{Ac}]$ was increased from 40 to $70 \mathrm{wt} \%$, with a step jump observed between 70 and $80 \mathrm{wt} \%$ followed by a gradual linear increase until pure $[\mathrm{C} 2 \mathrm{mim}][\mathrm{Ac}]$ was achieved. This result contrasted against the slight decrease in yield found for safflower whole seed biomass as the relative concentration of [C2mim] [Ac] was increased above 70 weight percent. It was hypothesized that the variation in yield response was a result of the jatropha whole seeds possessing a much harder and thicker shell as compared to safflower whole seeds which possess a thin shell that is difficult to separate from the kernel.

To confirm this hypothesis, the jatropha shell and kernel were independently pretreated and their hydrolysis yields investigated. Yields from the kernel biomass (data not shown) pretreated at $120^{\circ} \mathrm{C}$ in 70 and $100 \mathrm{wt} \%$ [C2mim] [Ac] were equivalent at $9 \mathrm{wt} \%$ total fermentable carbohydrates (relative to weight of kernel), inferring that $[\mathrm{C} 2 \mathrm{mim}][\mathrm{Ac}]$ concentration had negligible effect on the efficiency of subsequent enzymatic hydrolysis. By contrast, pretreatment of the jatropha shell with [C2mim][Ac] cosolvent (Figure 4) led to fermentable sugar profile similar to that of the jatropha whole seed (i.e., shell plus kernel, Figure 3) confirming that the presence of the jatropha shell is the source of the observed variation in fermentable sugar yields.

As anticipated, the yield of fermentable sugars from jatropha shell at $100^{\circ} \mathrm{C}$ were lower than that observed at $120^{\circ} \mathrm{C}$

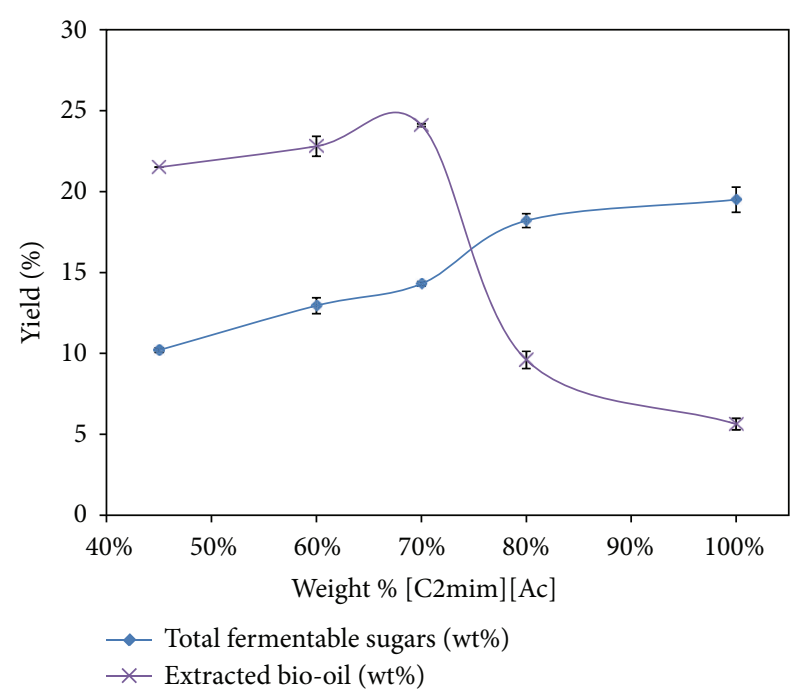

FIGURE 3: Total fermentable sugars and bio-oil yields relative to weight of whole seed obtained from pretreated jatropha whole seed (kernel plus shell) at different concentrations of [C2mim][Ac].

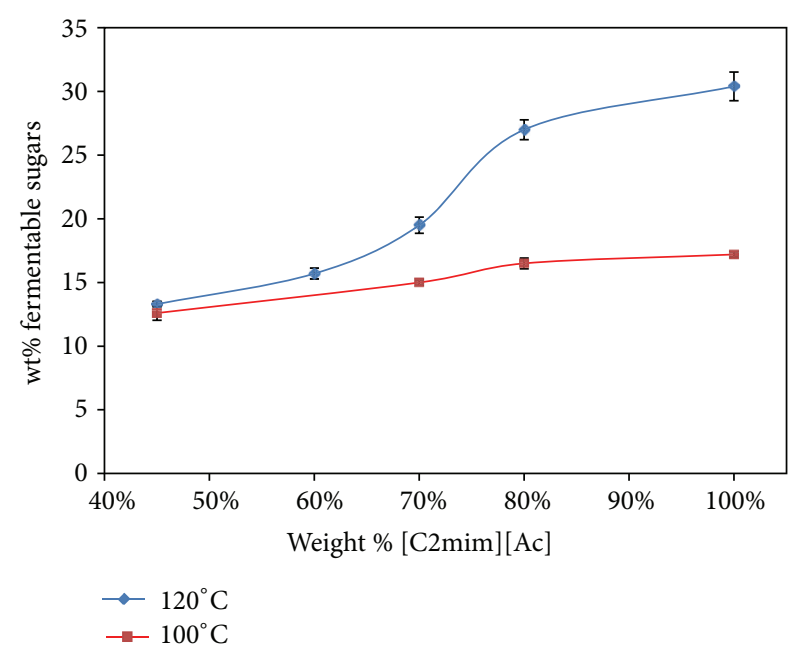

FIGURE 4: Total fermentable sugar yields relative to weight of jatropha shell released from jatropha shell at different temperatures after pretreatment.

with the biggest changes in yields occurring after $70 \mathrm{wt} \%$ [C2mim] $[\mathrm{Ac}]$. Unlike the safflower biomass (which does not contain a hard outer shell like jatropha), it appears that [C2mim] $\mathrm{Ac}]$ concentrations above $70 \mathrm{wt} \%$ are necessary to effectively disrupt the intermolecular bonds in the hard and thick jatropha shell [28]. The acetate anion enhances the separation of carbohydrates from the lignin protective matrix and also disrupts the hydrogen bonding between the cellulose microfibrils [14]. This can cause partial dissolution of the biomass into the solvent and, in expansion of the biomass matrix, all of which enhance the penetrability of the hydrolysis enzymes.

The xylose content from the jatropha shell for pretreatments in both pure and $80 \mathrm{wt} \%$ [C2mim][Ac] was quite similar (Table 4), indicating that hemicellulose was also 
TABLE 3: Weight percent fermentable sugars (relative to weight of whole seed) released from safflower whole seed pretreated with the cosolvent $[\mathrm{C} 2 \mathrm{mim}]\left[\mathrm{MeSO}_{4}\right]-\mathrm{MeOH}$.

\begin{tabular}{|c|c|c|c|c|c|c|}
\hline \multirow{3}{*}{$\begin{array}{l}\mathrm{Wt} \% \\
{[\mathrm{C} 2 \mathrm{mim}]\left[\mathrm{MeSO}_{4}\right]}\end{array}$} & \multicolumn{6}{|c|}{ Safflower whole seeds (wt\% glucose, xylose) ${ }^{\mathrm{a}}$} \\
\hline & \multicolumn{2}{|c|}{$64^{\circ} \mathrm{C}$} & \multicolumn{2}{|c|}{$100^{\circ} \mathrm{C}$} & \multicolumn{2}{|c|}{$120^{\circ} \mathrm{C}$} \\
\hline & glucose & xylose & glucose & xylose & glucose & xylose \\
\hline $45 \%$ & 10.5 & 2.3 & 9.9 & 2.4 & - & - \\
\hline $70 \%$ & 10.8 & 2.3 & 11 & 2.2 & 10.6 & 2.5 \\
\hline $100 \%$ & - & - & - & - & 11.5 & 2.2 \\
\hline
\end{tabular}

${ }^{\mathrm{a}}$ The reported values represent repeated HPLC measurements that have been verified to vary by no more than four percent of the reported values.

TABLE 4: Weight percent fermentable sugars (relative to weight of jatropha whole seed or jatropha shell) recovered from jatropha whole seed and jatropha shell pretreated with the cosolvent [C2mim][Ac]-MeOH at 100 and $120^{\circ} \mathrm{C}$.

\begin{tabular}{lcccccc}
\hline \multirow{2}{*}{ wt\% ionic liquid } & \multicolumn{2}{c}{ Jatropha whole seed ${ }^{\mathrm{a}, \mathrm{c}}$} & \multicolumn{2}{c}{ Jatropha shell $^{\mathrm{b}, \mathrm{d}}$} \\
& \multicolumn{2}{c}{$120^{\circ} \mathrm{C}$} & glucose & xylose & glucose & xylose \\
\hline $45 \%$ & $9.1(0.1)$ & $1.1(0.0)$ & $10.8(0.3)$ & $1.8(0.1)$ & $11.2(0.1)$ & $2.1(0.0)$ \\
$60 \%$ & $10.8(0.3)$ & $2.1(0.0)$ & - & - & $12.6(0.3)$ & $3.1(0.0)$ \\
$70 \%$ & $11.7(0.0)$ & $2.6(0.1)$ & $12.2(0.1)$ & $2.8(0.1)$ & $14.2(0.6)$ & $5.3(0.2)$ \\
$80 \%$ & $14.1(0.3)$ & $4.1(0.0)$ & $13.3(0.2)$ & $3.2(0.2)$ & $17.7(0.4)$ & $9.3(0.0)$ \\
$100 \%$ & $15.5(0.3)$ & $4.0(0.3)$ & $14.1(0.1)$ & $3.1(0.1)$ & $21.7(0.7)$ & $8.7(0.2)$ \\
\hline
\end{tabular}

${ }^{\mathrm{a}, \mathrm{b}}$ The reported data are averages of at least two samples. The values in brackets are the deviations of the measured values from the mean.

${ }^{c} J a t r o p h a$ whole seed fermentable sugar values are relative to weight of jatropha whole seed.

d Jatropha shell fermentable sugar values are relative to weight of jatropha shell.

digested to the same extent. Thus, the slight difference in total fermentable sugars $(3.4 \mathrm{wt} \%)$ recovered from the jatropha shell using pretreatments of pure or $80 \mathrm{wt} \%$ [C2mim][Ac] at $120^{\circ} \mathrm{C}$ is predominately due to the incomplete utilization of cellulose during the enzyme hydrolysis of the shell in $80 \mathrm{wt} \%$ [C2mim] [Ac]. That said, the small difference in yield (i.e., $3.4 \mathrm{wt} \%$ ) does suggest that the sole pretreatment of jatropha shell can effectively be executed using only $80 \mathrm{wt} \%$ [C2mim] $[\mathrm{Ac}]$ at $120^{\circ} \mathrm{C}$ if one desire to use less ionic liquid.

To estimate the efficiency relative to the carbohydrate fraction of the oil seed biomass (as opposed to the amount of whole seed biomass as reported previously and in the tables) the amounts of recovered fermentable sugars were converted to hydrolyzed carbohydrates (cellulose and hemicellulose) using 0.9 and 0.88 as conversion factors for glucose and xylose concentrations to cellulose and hemicellulose, respectively. These values were then used to estimate the carbohydrate fraction of the whole seeds (i.e., $29 \mathrm{wt} \%$ and $22 \mathrm{wt} \%$ for safflower and jatropha, resp.). The calculations indicate that the $[\mathrm{C} 2 \mathrm{mim}][\mathrm{Ac}]$ cosolvent yields carbohydrate recovery efficiencies (relative to the baseline carbohydrate content of the whole seeds) as high as $74 \%$ achieved at $80 \mathrm{wt} \%$ [C2mim] [Ac] on jatropha and $78 \%$ with $70 \mathrm{wt} \%$ [C2mim] [Ac] on safflower seeds.

3.2. Coextraction of Bio-Oil. Both safflower and jatropha seeds contain significant amounts of bio-oil and its coextraction during the pretreatment step is desired. Previous reports on the extraction of bio-oil from jatropha kernel [24] using the cosolvent system at $64^{\circ} \mathrm{C}$ have shown a nonlinear response in yield to ionic liquid weight percent. Thus, we
TABLE 5: Bio-oil yields relative to weight of whole seed from safflower whole seed treated with the cosolvent [C2mim] $[\mathrm{Ac}]-\mathrm{MeOH}$ at $120^{\circ} \mathrm{C}$.

\begin{tabular}{lc}
\hline wt\% ionic liquid & $\begin{array}{c}\text { Safflower }^{\mathrm{a}} \\
(\mathrm{wt} \% \text { bio-oil) }\end{array}$ \\
\hline $45 \%$ & $37.5(0.4)$ \\
$70 \%$ & $35.8(1.5)$ \\
$100 \%$ & $30.5(0.5)$ \\
\hline
\end{tabular}

${ }^{\mathrm{a}}$ The reported data are averages of two samples. The values in brackets are the deviations of the measured values from the mean.

characterized the extraction of bio-oil from jatropha whole seed biomass at a pretreatment temperature of $120^{\circ} \mathrm{C}$. As seen in Figure 3, maximum oil yields are observed at [C2mim] [Ac] concentrations approaching $70 \mathrm{wt} \%$ after which a significant drop off in yield was observed. For the purpose of multicomponent extraction of bio-oil and recovery of fermentable sugars, Figure 3 suggests an optimal [C2mim][Ac]-methanol ratio of $70: 30 \mathrm{wt} \%$.

Similar to that found previously for jatropha oil seeds [24], pretreatments of safflower whole seed using [C2mim] [Ac] concentrations between 45 and $70 \mathrm{wt} \%$ produced the highest extracted bio-oil yields (Table 5). Pure [C2mim] [Ac] provided the least efficient bio-oil yield at $30.5 \mathrm{wt} \%$ (relative to whole seed) providing further confirmation that $70 \mathrm{wt} \%$ $[\mathrm{C} 2 \mathrm{mim}][\mathrm{Ac}]$ is more appropriate for the effective multicomponent extraction of biooil and fermentable sugars from both safflower and jatropha whole seeds. 


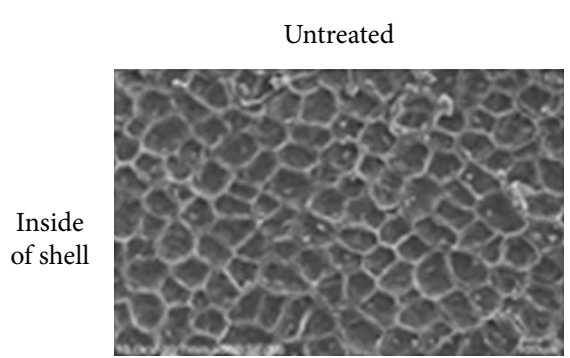

(a)

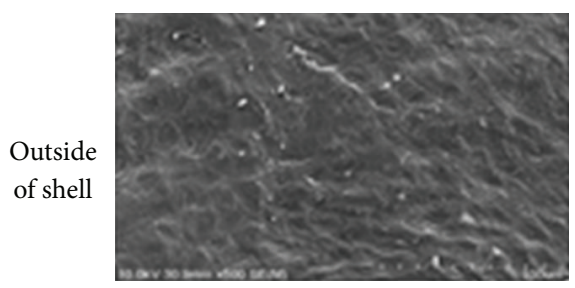

(d)

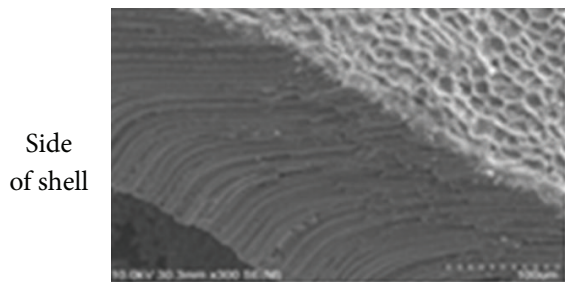

$(\mathrm{g})$

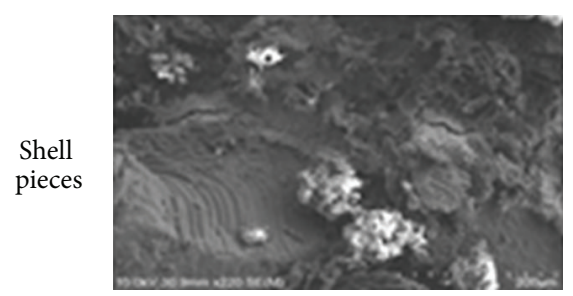

(j)

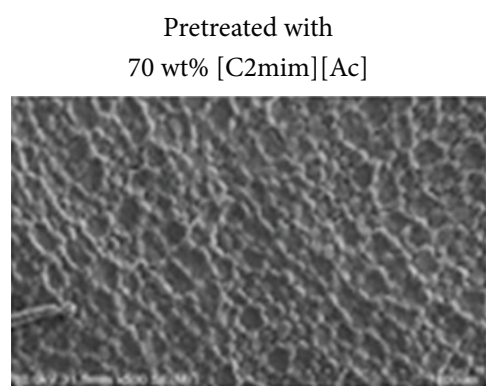

(b)

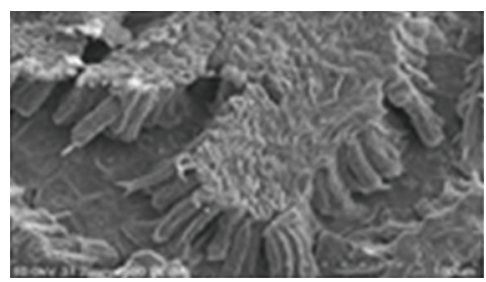

(e)

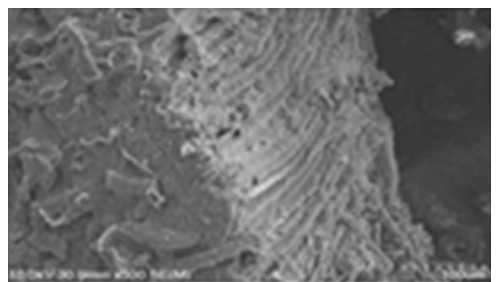

(h)

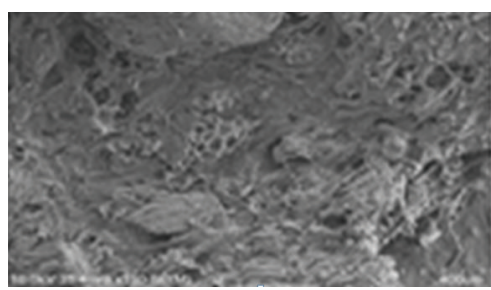

(k)

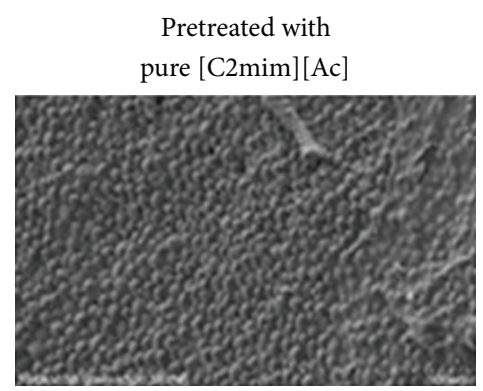

(c)

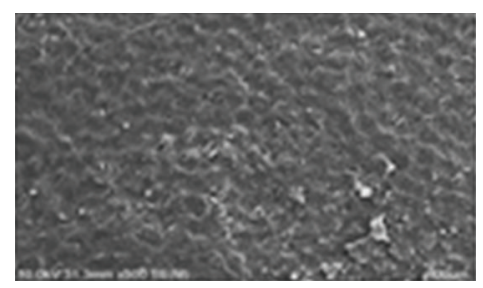

(f)

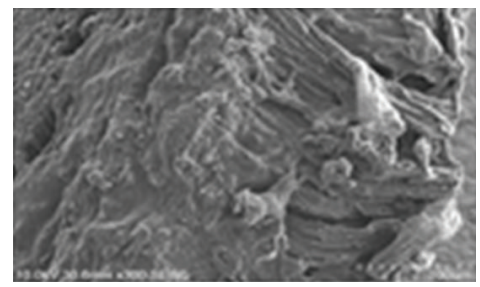

(i)

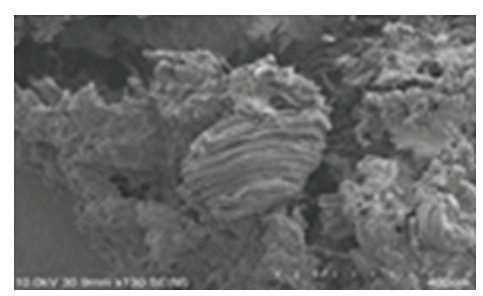

(1)

FIGURE 5: SEM images of jatropha shell taken at $100 \mu \mathrm{m},((\mathrm{a})-(\mathrm{i})), 200 \mu \mathrm{m}(\mathrm{j})$, and $400 \mu \mathrm{m}((\mathrm{k})-(\mathrm{l}))$.

3.3. SEM Analysis of Pretreated Biomass. The jatropha shell was found to be the most difficult component to enzymatically hydrolyze as evidenced by the large variation of fermentable sugar yields with ionic liquid concentration. To confirm this finding, the pretreated jatropha shell was visualized using high-resolution imaging (Figure 5). The micrographs of untreated shell (control) showed intact rodlike fibril structure and smooth outside surface. A surface layer covering the fibril cell structure can be seen from the inside view of the shell. No singular or loose fibers were observed in the untreated shell. SEM images of treated shells showed significant difference between untreated and pretreated (70 wt $[\mathrm{C} 2 \mathrm{mim}][\mathrm{Ac}]$ and pure $[\mathrm{C} 2 \mathrm{mim}][\mathrm{Ac}])$ jatropha shell biomass. For example, the pure [C2mim][Ac] pretreated shell possessed a loose distorted fiber structure and pores (Figures 5(i) and 5(1)) likely due to the delignification of the biomass. The inside surface layer of the jatropha shell was entirely removed during pretreatment exposing the top surface of the fibril structure (Figure 5(c)). The $70 \%$ $(\mathrm{w} / \mathrm{w})[\mathrm{C} 2 \mathrm{mim}][\mathrm{Ac}]$ pretreated jatropha shell showed similar disruption of the biomass though to a slightly less extent than pure [C2mim][Ac]. The SEM analysis supports the enzyme hydrolysis data which showed high fermentable sugar yields with $70 \mathrm{wt} \%$ [C2mim][Ac] and pure [C2mim][Ac]. Improved contact between the enzyme and biomass occurs due to the disruption of the outer surface layers of the jatropha shell, distortion and loosening of the fiber structure, and creation of pore structure aids in enzyme hydrolysis of the jatropha shell.

\section{Systems Analysis}

The commercialization of a fuel from oil seed industry will be enhanced by the utilization of multiple components such as proteins, carbohydrates, and lignin to compensate for the marginal market value of the bio-oil product. As the ionic liquid cosolvent system reported in this work appears to support 


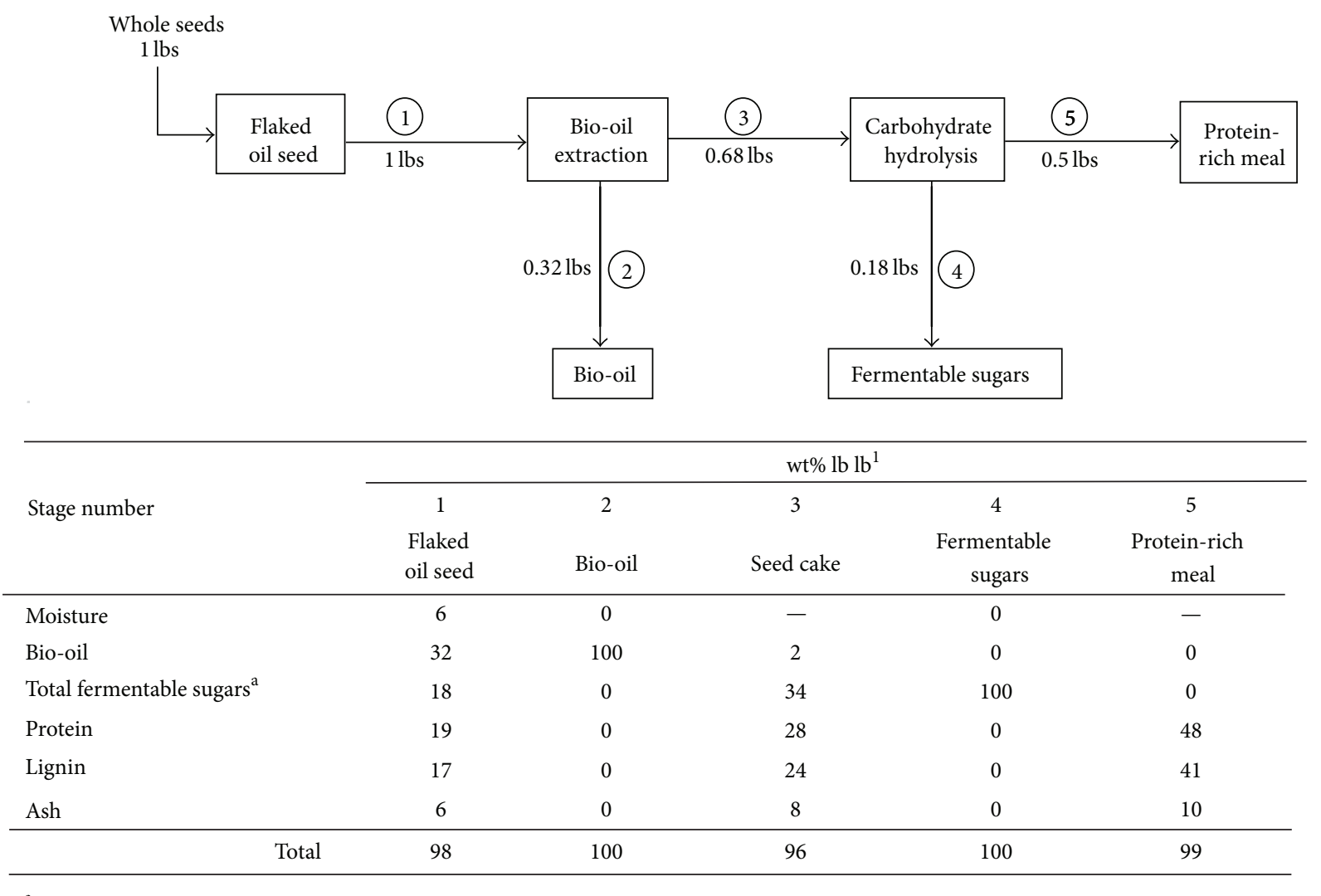

${ }^{\mathrm{a}}$ Taken as a two to one ratio of glucose to xylose

FiguRE 6: Mass balances for solvent extraction of jatropha whole seed and composition of the intermediate stages. Whole jatropha seed taken to comprise moisture (6\%), bio-oil (32\%), total fermentable sugars (18\%), protein (19\%), lignin (17\%), and ash (6\%). The values in the tables are averages taken from the literature and consequently do not always sum to precisely 100 [5-8].

pathways for additional byproducts, we have attempted a first pass systems' analysis that evaluates two specific pathways to process jatropha oil seed into the following products: (1) fermentable sugars, (2) bio-oil, and (3) protein-rich meal.

The first pathway begins with the flaking of the jatropha whole seed (Figure 6). The flaked jatropha whole seed is assumed treated with the ionic liquid based cosolvent as discussed previously. The top bio-oil phase is assumed fully recovered leaving behind the cosolvent and digested biomass. The cosolvent phase is also recovered and recycled whilst the cosolvent pretreated biomass (seed cake) is hydrolyzed with enzymes to convert the structural carbohydrates into fermentable sugars (e.g., glucose and xylose). The proteinrich biomass remaining after carbohydrate extraction is assumed desolvatized for use as a supplement to animal feed. A mass balance (assuming complete recovery of the biooil, carbohydrates, and protein-rich meal from the whole seeds) applied to this pathway suggests that 1 pound of jatropha whole seed yields approximately 0.18 pounds of fermentable sugars, 0.32 pounds of bio-oil, and 0.50 pounds of protein-rich meal. The analysis also assumes effective biooil and carbohydrate recovery which is expected to occur as a result of multiple cosolvent extraction cycles performed in a multistage countercurrent extractor or by accelerated solvent extraction techniques. A preliminary energy analysis based on inputs (jatropha whole seeds) and outputs (biooil, carbohydrates, and protein-rich meal) was performed to ascertain the feasibility of jatropha processing. The results, shown in Table 6, approximate a significant energy recovery of $10,954 \mathrm{Btu}$ and a positive cost analysis of $\$ 0.77$ recovered per pound of whole jatropha seed processed. The cost analysis was estimated from the market prices of inputs and outputs of soybean processing and is presented as an approximate indicator of profitability (see Table 6).

Based upon the heats of combustion of the products from the first pathway, roughly $99 \%$ of energy available in the jatropha whole seed is recovered compared to only $49 \%$ if only the bio-oil is recovered. The energy analysis does not include the processing energy inputs for the pretreatment and hydrolysis steps; thus, inclusion of this input energy is anticipated to lower the overall system efficiency. More, we propose the conversion of the carbohydrate fraction to fermentable sugars (can be used for fermentation of biooils or alcohols) as preferable to its use as an animal feed (particularly given that the presence of any level of phorbol ester toxins complicates its use in this manner) $[29,30]$.

The second pathway considered likewise begins with the whole seed but processes only the kernel after it has been 
TABLE 6: Energy and price balances from jatropha whole seed processing using first and second pathways.

\begin{tabular}{|c|c|c|}
\hline & First pathway & Second pathway \\
\hline Heat of combustion inputs (Btu/lb whole seed $)^{a}$ & 10963 & 10963 \\
\hline Heat of combustion outputs (Btu/lb whole seed $)^{\mathrm{b}}$ & 10954 & 7586 \\
\hline$\%$ recovery & 99 & 69 \\
\hline costs of feedstock/lb ${ }^{c}$ & 0.22 & 0.22 \\
\hline market value of products/lb of whole seed ${ }^{\mathrm{d}}$ & 0.99 & 0.55 \\
\hline$\%$ profit & 350 & 150 \\
\hline
\end{tabular}

${ }^{a}$ Heat of combustion of inputs stated as that of jatropha whole seed [9].

${ }^{b}$ Heats of combustion of outputs obtained from jatropha oil (17498 Btu/lb), fermentable sugars (glucose (6700 Btu/lb) and xylose (6710 Btu/lb) in $2: 1$ ratio) and protein-rich meal (calculated from kernel cake $(7825 \mathrm{Btu} / \mathrm{lb})$ and seed cake $(10791 \mathrm{Btu} / \mathrm{lb})$ by substracting the contribution from carbohydrate components) $[5,9,10]$.

${ }^{\mathrm{c}}$ Costs of inputs estimated from commodity price of soybean whole seed [11].

${ }^{\mathrm{d}}$ Price of protein-rich meal and bio-oil estimated from soybean and fermentable sugars from $25 \mathrm{~kg}$ glucose at Sigma Aldrich [11].

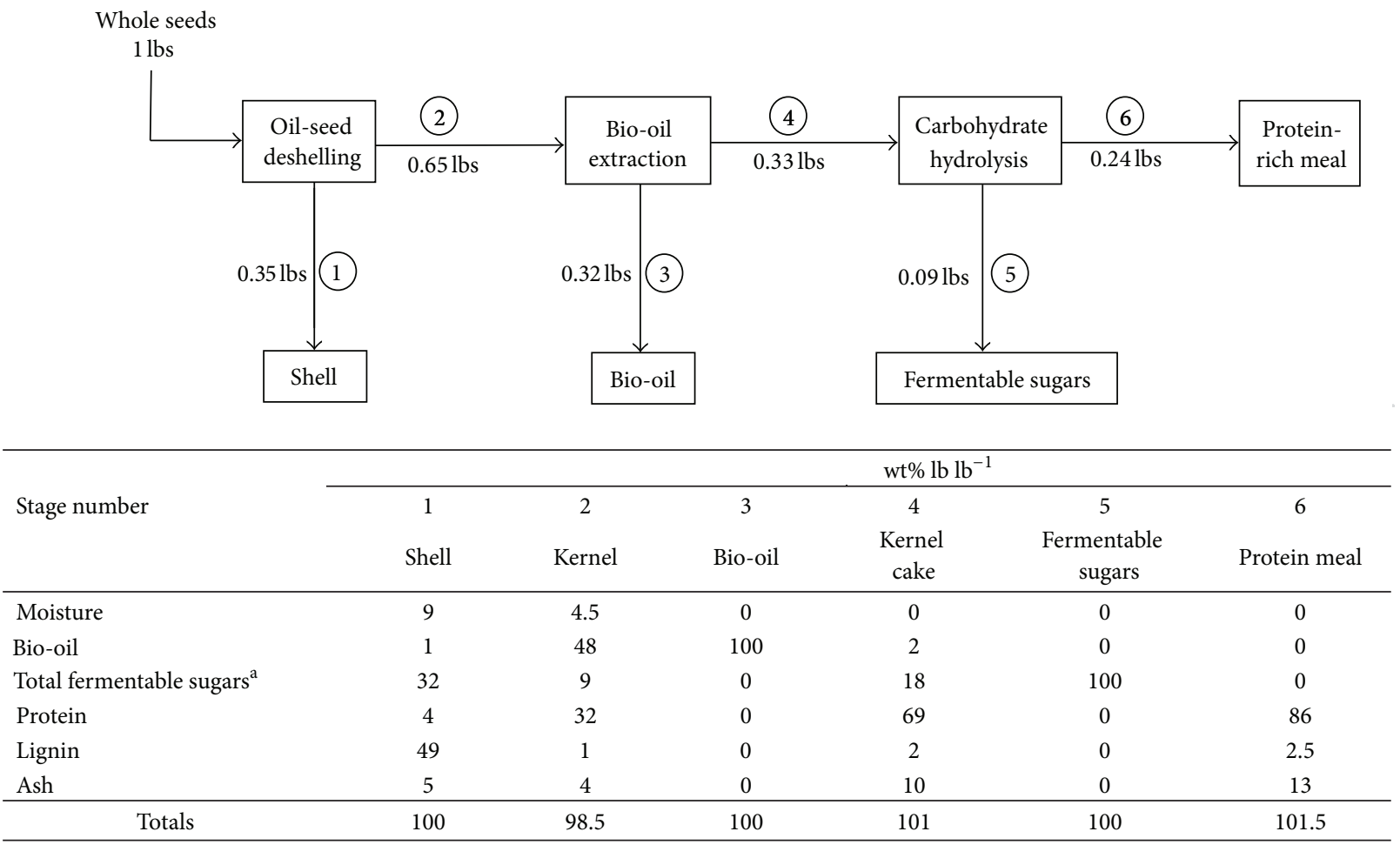

${ }^{a}$ Taken as a two to one ratio of glucose to xylose

FIGURE 7: Mass balances for solvent extraction of jatropha kernel and the composition of intermediate stages. Whole jatropha seed taken to comprise moisture (6\%), bio-oil (32\%), total fermentable sugars (18\%), protein (19\%), lignin (17\%), and ash (6\%). The values in table are averages taken from the literature and consequently do not always sum to precisely 100 [5-8].

separated from the shells (Figure 7). The separation of the shell from the kernel theoretically improves the yield of biooil recovered per unit volume of biomass processed but at the cost of lowering the yield of fermentable sugars. In our example, 1 pound of jatropha whole seed yields 0.65 pounds of kernel which produces approximately 0.09 pounds of fermentable sugars, 0.32 pounds of bio-oil, and 0.24 pounds of protein-rich meal. As seen in Table 6, the second pathway recovers a lower amount of energy (69\% of caloric value of whole seed) and our cost analysis suggests a profit of $\$ 0.33$ per pound processed. However, the energy balance and cost analysis improve if only the bio-oil is extracted.

\section{Conclusions}

In this study, an ionic liquid, methanol cosolvent was shown for the first time to effectively extract bio-oil and recover fermentable sugars from oil-seed biomass. This represents an improvement over current approaches that have focused solely on the recovery of bio-oil or fermentable sugars [3]. Effective co-recovery of both bio-oil and fermentable sugars was shown to require both cosolvent components with an optimal concentration of $70-30 \mathrm{wt} \%$ [C2 $\mathrm{mim}]$ [Ac] to methanol ratio and a processing temperature of $120^{\circ} \mathrm{C}$. Under these conditions, nearly all the bio-oil (35.8 and $24.1 \mathrm{wt} \%$ 
relative to weight of whole seed) was extracted and autopartitioned to a separate immiscible phase and approximately 25.4 and $14.3 \mathrm{wt} \%$ (relative to weight of whole seed) of fermentable sugars were recovered from the safflower and jatropha whole seeds, respectively. This constitutes a combined carbohydrate and bio-oil co-recovery of 61.2 and $38.4 \mathrm{wt} \%$ of the safflower and jatropha whole seeds, demonstrating a new pathway for processing increased products from oil-seed biomass. A first pass model analysis suggested that the most optimal processing pathway would be to pretreat the jatropha whole seed with the cosolvent and recover bio-oil, fermentable sugars, and a protein-rich meal.

\section{Conflict of Interests}

The authors confirm that there is no conflict of interests with regard to financial gain for any of the companies or entities referred to in the Methods section of the paper from which reagents, chemicals, and other materials were purchased. Funding from this work was solely as stated in the acknowledgement and no interaction occurred with the mentioned commercial entities commercial identities (i.e., Fisher scientific, Aldrich, Novozymes Inc., and Sigma Aldrich) other than to purchase chemicals, reagents, or materials from them through typical catalogue purchase.

\section{Acknowledgments}

The authors acknowledge financial support from the Office of Naval Research (N00014-10-1-0310) and SuGanit Systems Inc. The authors would also like thank Jonathan Deenik and Pacific Biodiesel for donating the seeds.

\section{References}

[1] A. T. W. M. Hendriks and G. Zeeman, "Pretreatments to enhance the digestibility of lignocellulosic biomass," Bioresource Technology, vol. 100, no. 1, pp. 10-18, 2009.

[2] M. Cooney, G. Young, and N. Nagle, "Extraction of bio-oils from microalgae," Separation and Purification Reviews, vol. 38, no. 4, pp. 291-325, 2009.

[3] M. Mora-Pale, L. Meli, T. V. Doherty, R. J. Linhardt, and J. S. Dordick, "Room temperature ionic liquids as emerging solvents for the pretreatment of lignocellulosic biomass," Biotechnology and Bioengineering, vol. 108, no. 6, pp. 1229-1245, 2011.

[4] H. E. Synder and T. W. Kwon, Soybean Utilization, Van Nostrand Reinhold, New York, NY, USA, 1987.

[5] W. M. J. Achten, L. Verchot, Y. J. Franken et al., "Jatropha biodiesel production and use," Biomass and Bioenergy, vol. 32, no. 12, pp. 1063-1084, 2008.

[6] R. Staubmann, "Biogas production from Jatropha curcas presscake," Applied Biochemistry and Biotechnology A, vol. 63-65, no. 1-3, pp. 457-467, 1997.

[7] Y. Liang, T. Siddaramu, J. Yesuf, and N. Sarkany, "Fermentable sugar release from Jatropha seed cakes following lime pretreatment and enzymatic hydrolysis," Bioresource Technology, vol. 101, no. 16, pp. 6417-6424, 2010.

[8] A. M. J. Kootstra, H. H. Beeftink, and J. P. M. Sanders, "Valorisation of Jatropha curcas: solubilisation of proteins and sugars from the $\mathrm{NaOH}$ extracted de-oiled press cake," Industrial Crops and Products, vol. 34, no. 1, pp. 972-978, 2011.

[9] K. Openshaw, "A review of Jatropha curcas: an oil plant of unfulfilled promise," Biomass and Bioenergy, vol. 19, no. 1, pp. 1-15, 2000.

[10] M. A. V. R. da Silvaa, M. D. M. C. R. da Silvaa, A. I. M. C. L. Ferreiraa, Q. Shib, B. F. Woodfieldb, and R. N. Goldbergc, “Thermochemistry of alpha-D-xylose(cr)," Journal of Chemical Thermodynamics, vol. 58, pp. 20-28, 2012.

[11] USDA, Oilseeds: World Markets and Trade, United States Department of Agriculture, 2013.

[12] T. Adriaans, "Suitability of solvent extraction for Jatropha curcas," Ingenia Consultants and Engineers, for FACT Foundation, 2006.

[13] M. J. Cooney and C. K. H. Guay, "Heterotrophic algal-biodiesel production: challenges and opportunities," in Biofuel and Bioenergy from Biowastes and Lignocellulosic Biomass, S. K. Khanal, Ed., pp. 346-370, American Society of Civil Engineers, 2010.

[14] G. Brodeur, E. Yau, K. Badal, J. Collier, K. B. Ramachandran, and S. Ramakrishnan, "Chemical and physicochemical pretreatment of lignocellulosic biomass: a review," Enzyme Research, vol. 2011, Article ID 787532, 17 pages, 2011.

[15] L. C. Sousa, S. P. Chundawat, V. Balan, and B. E. Dale, “'Cradleto-grave' assessment of existing lignocellulose pretreatment technologies," Current Opinion in Biotechnology, vol. 20, no. 3, pp. 339-347, 2009.

[16] H. Zhao, G. A. Baker, and J. V. Cowins, "Fast enzymatic saccharification of switchgrass after pretreatment with ionic liquids," Biotechnology Progress, vol. 26, no. 1, pp. 127-133, 2010.

[17] C. Li, B. Knierim, C. Manisseri et al., "Comparison of dilute acid and ionic liquid pretreatment of switchgrass: biomass recalcitrance, delignification and enzymatic saccharification," Bioresource Technology, vol. 101, no. 13, pp. 4900-4906, 2010.

[18] I. P. Samayam, B. L. Hanson, P. Langan, and C. A. Schall, "Ionicliquid induced changes in cellulose structure associated with enhanced biomass hydrolysis," Biomacromolecules, vol. 12, no. 8, pp. 3091-3098, 2011.

[19] R. P. Swatloski, S. K. Spear, J. D. Holbrey, and R. D. Rogers, "Dissolution of cellose with ionic liquids," Journal of the American Chemical Society, vol. 124, no. 18, pp. 4974-4975, 2002.

[20] Ionic Liquids, B. Kirchner, Ed., vol. 290 of Topics in Current Chemistry, Springer, New York, NY, USA, 2009.

[21] X. Zhao, K. Cheng, and D. Liu, "Organosolv pretreatment of lignocellulosic biomass for enzymatic hydrolysis," Applied Microbiology and Biotechnology, vol. 82, no. 5, pp. 815-827, 2009.

[22] M. Zavrel, D. Bross, M. Funke, J. Büchs, and A. C. Spiess, "Highthroughput screening for ionic liquids dissolving (ligno-)cellulose," Bioresource Technology, vol. 100, no. 9, pp. 2580-2587, 2009.

[23] Y. Pu, N. Jiang, and A. J. Ragauskas, "Ionic liquid as a green solvent for lignin," Journal of Wood Chemistry and Technology, vol. 27, no. 1, pp. 23-33, 2007.

[24] G. Severa, G. Kumar, M. Troung, G. Young, and M. J. Cooney, "Simultaneous extraction and separation of phorbol esters and bio-oil from Jatropha biomass using ionic liquid-methanol cosolvents," Separation and Purification Technology, vol. 116, pp. 265-270, 2013.

[25] G. Young, F. Nippgen, S. Titterbrandt, and M. J. Cooney, "Lipid extraction from biomass using co-solvent mixtures of ionic liquids and polar covalent molecules," Separation and Purification Technology, vol. 72, no. 1, pp. 118-121, 2010. 
[26] G. Young, F. Nippgen, S. Titterbrandt, and M. J. Cooney, "Lipid extraction from biomass using co-solvent mixtures of ionic liquids and polar covalent molecules," Separation and Purification Technology, vol. 72, no. 1, pp. 118-121, 2010.

[27] Z. Wei, Y. Zu, Y. Fu et al., "Ionic liquids-based microwaveassisted extraction of active components from pigeon pea leaves for quantitative analysis," Separation and Purification Technology, vol. 102, pp. 75-81, 2013.

[28] D.-A. Z. Wever, H. J. Heeres, and A. A. Broekhuis, "Characterization of physic nut (Jatropha curcas L.) shells," Biomass and Bioenergy, vol. 37, pp. 177-187, 2012.

[29] H. P. S. Makkar, K. Becker, F. Sporer, and M. Wink, "Studies on nutritive potential and toxic constituents of different provenances of Jatropha curcas," Journal of Agricultural and Food Chemistry, vol. 45, no. 8, pp. 3152-3157, 1997.

[30] J. Martínez-Herrera, P. Siddhuraju, G. Francis, G. Dávila-Ortíz, and K. Becker, "Chemical composition, toxic/antimetabolic constituents, and effects of different treatments on their levels, in four provenances of Jatropha curcas L. from Mexico," Food Chemistry, vol. 96, no. 1, pp. 80-89, 2006. 

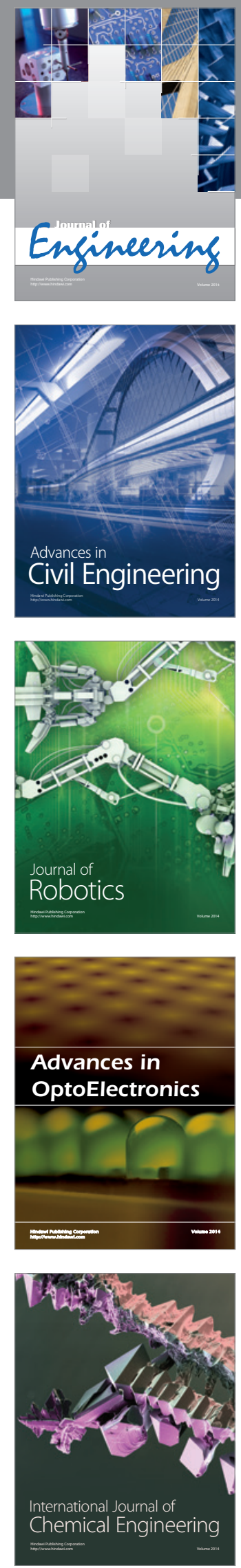

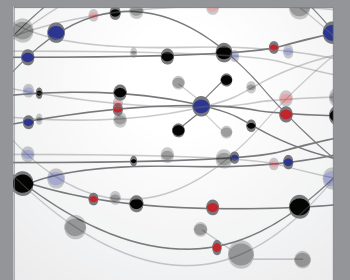

The Scientific World Journal
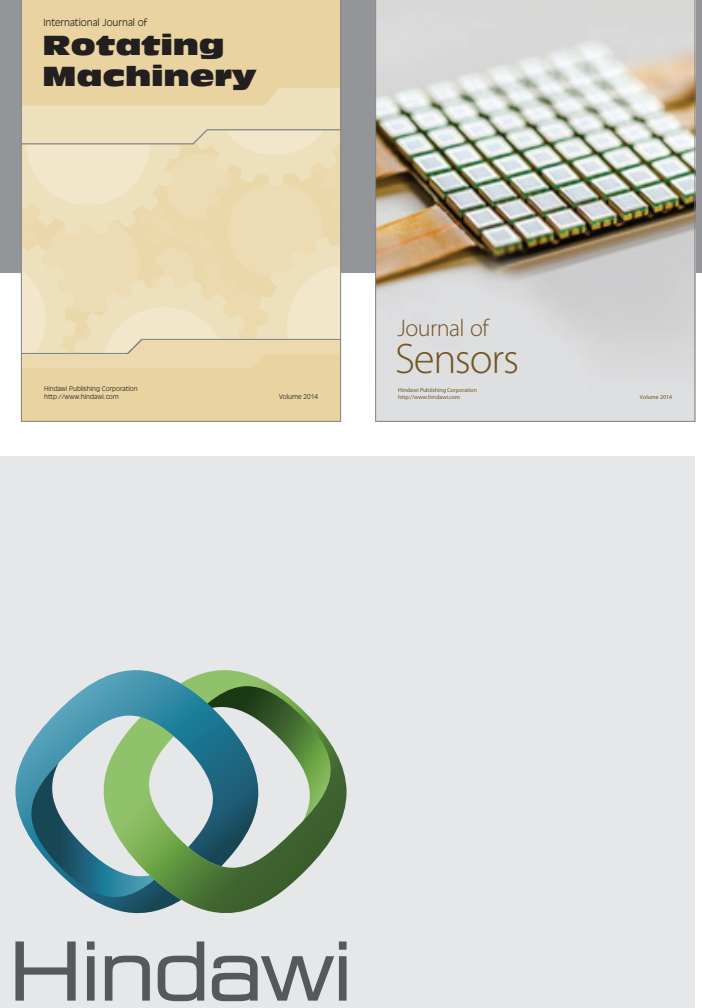

Submit your manuscripts at http://www.hindawi.com
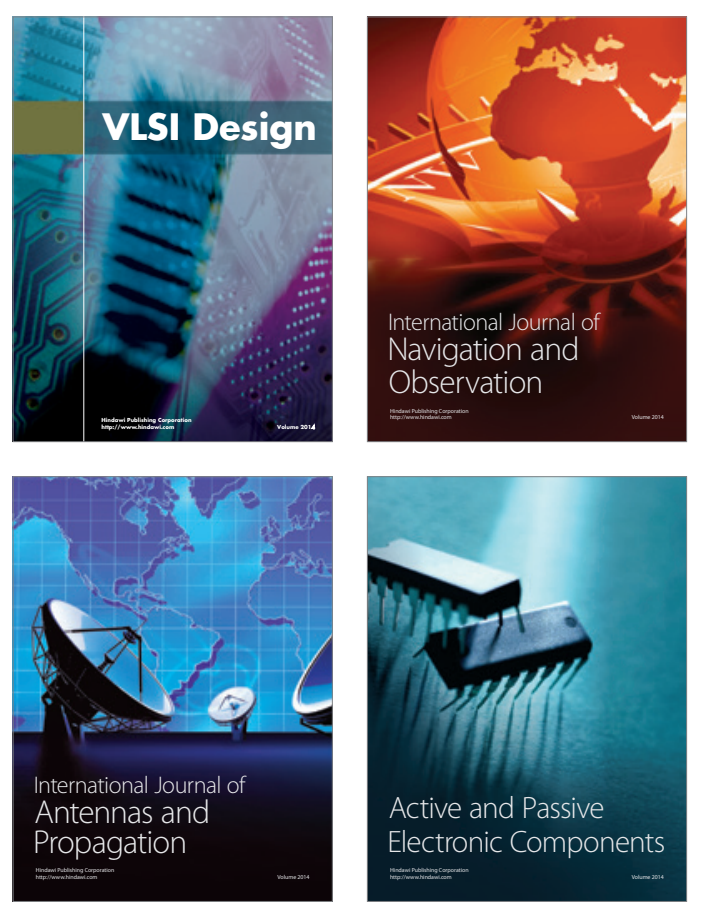
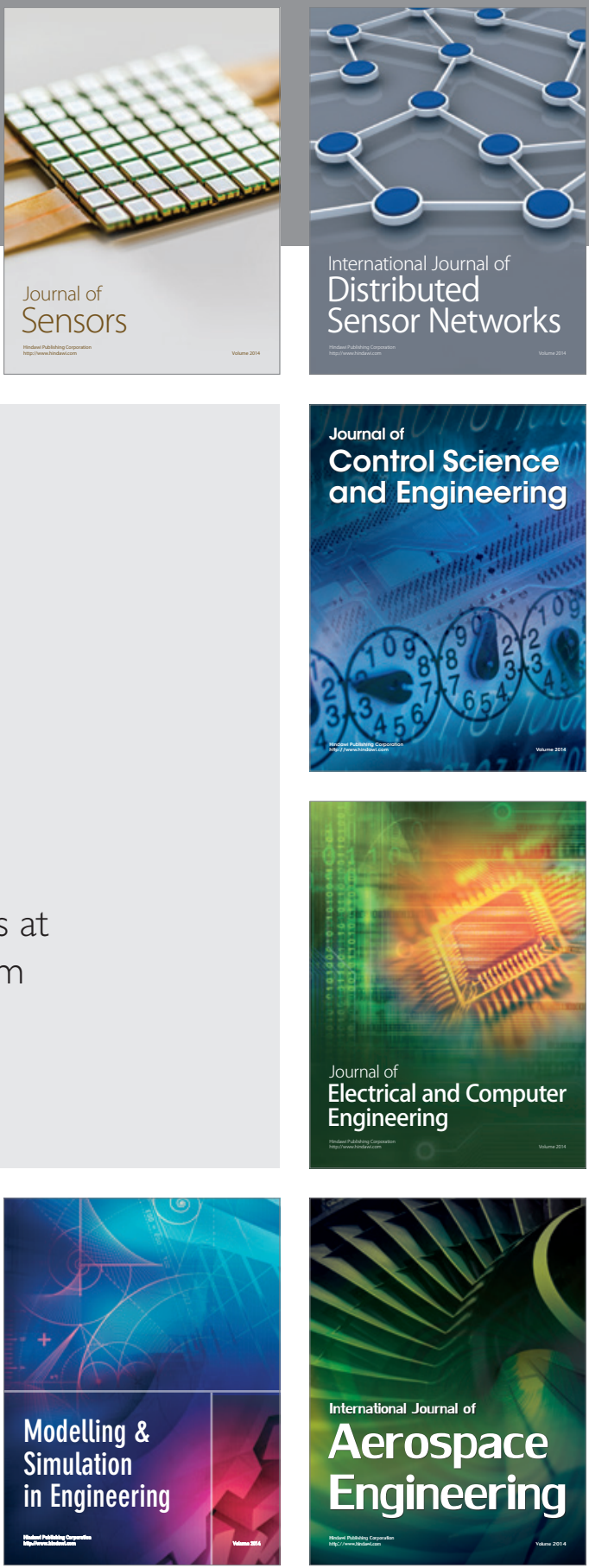

Journal of

Control Science

and Engineering
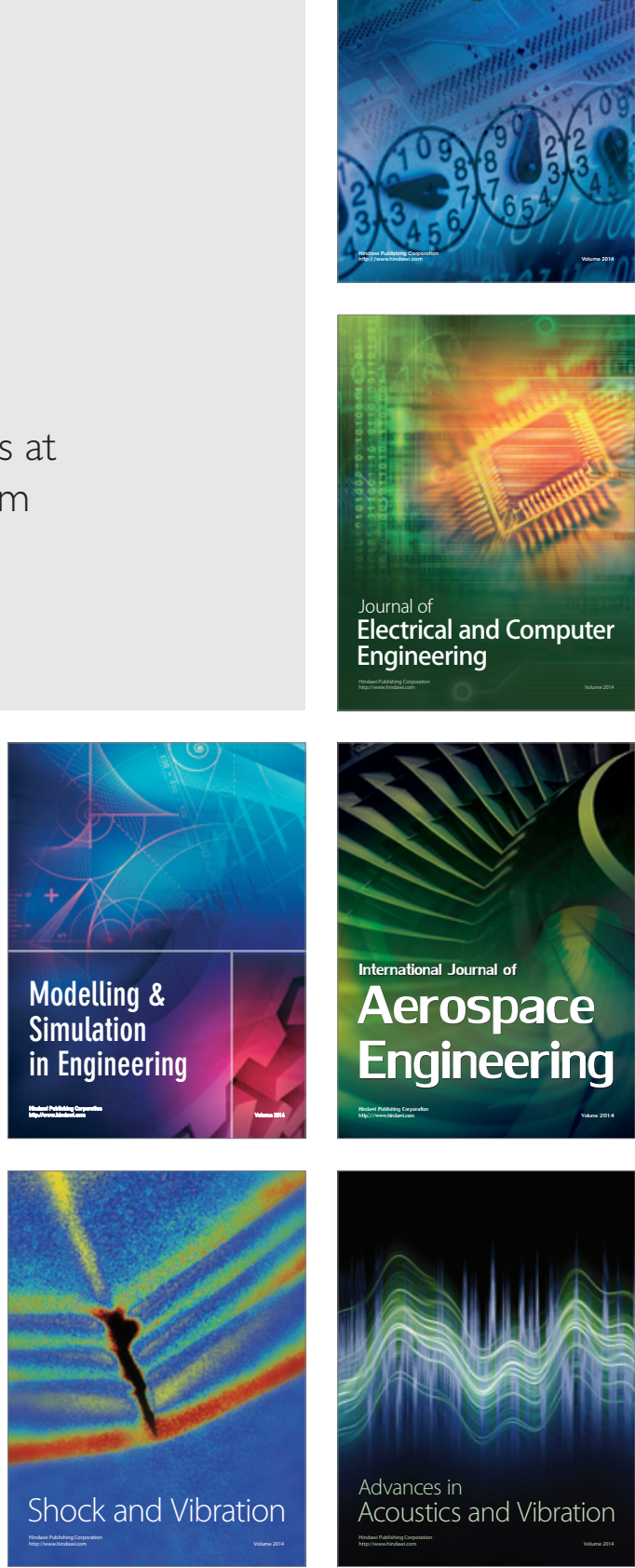